\title{
Reflections on Microscopy \& Analysis: From Viewing the Small World to Leading on a Larger Stage
}

\author{
DB Williams, President, The University of Alabama in Huntsville.
}

It is an extraordinary honor to receive the Henry Clifton Sorby Lifetime Achievement award of the International Metallographic Society. This award presents an opportunity for me to reflect on a lifetime of metallography and some of the lessons I learned, which may be of value to younger practitioners of the art. Described as "The greatest scientist that Sheffield has ever produced", Sorby pioneered the microscopy of meteorites and invented the "Spectrum Microscope". I was raised a scant thirty miles from where Sorby first practiced metallography. Much of my career has involved metallography of meteorites and various aspects of spectroscopy in the microscope. So perhaps there is some method to the IMS award committee's madness.

More than 40 years ago, I first sketched a metallographic image by hand. Within the subsequent 4 decades, single-atom imaging and analysis has become routine. So this abstract does not look out of place in the proceedings, I have included figures demonstrating such changes. However, few metallographers and fewer "spectrum microscopists", have descended all the way to the level of a senior university administrator, president or chancellor. While traveling this route, I have benefited from several fundamental lessons I learned on the way:

First, pick a technical area at which you excel, build on it, never stray too far from it, ensure you are always at its cutting edge. Excellence rarely comes in more than one area and administrators find it easier to fertilize existing excellence than to sow new seeds.

Second, technical support is more important than instruments. Great work is done on average microscopes that operate more often than their top of the line counterparts that may not deliver to their limits. Likewise great work is done at "average" universities, by extraordinary faculty with no ambitions to make it to the top of the line institutions.

Third, partner with colleagues, hire students and post docs who are better than you in various skill sets. They are your leadership team. My own success in the metallography field has come through partnerships with the best from Joe Goldstein and his meteorites to Masashi Watanabe's amazing single-atom analysis. Forming any leadership team is easy if you are prepared to attract and give credit to those who outshine you.

Fourth, attend professional meetings. Woody Allen once said: " $90 \%$ of life is just showing up". There is no substitute for meeting, listening, arguing with colleagues, in the conference room or the bar. No matter how inexperienced or how small your lab., your colleagues will eventually expect you there and not be surprised by your presence.

Fifth, hone your oral and written communication skills. Funding and publishing is all about sales and marketing. Average ideas, well presented will always impress more than brilliant work that is poorly presented. The same is true of any administrative concept. I have spent my academic life at small US universities, but have managed to take those places to levels where bigger and better institutions recognize their value. With my 
colleagues at Lehigh, we built the largest EM of materials lab. in the US, the best and longest-lasting EM education courses in the world and, at one time, the only university lab. in the world with two aberration-corrected AEMs. At UAHuntsville we have just become the smallest university in the Carnegie Foundation's "very high research activity" tier. Much of this success was built on some of the five lessons listed above.

Experience from the larger stage of academic leadership brings other issues to the fore, which have as much relevance for metallographers as for other researchers. For example:

1) Should the funding agencies develop special opportunities for proven researchers?

2) Should we mend the overloaded and dysfunctional peer-review system?

3) Should agencies and journals keep track of reviewers who use other author's ideas?

4) Should funding agencies demand a measurable return on their investments?

5) Is there a future for scientific research in a nation that does not recognize the value of, and the necessity for, an academic elite functioning within a meritocracy?

The talk will present my views on these and other questions, from the point of view of one of the many bloated, unproductive, top-heavy university administrators intent only on preventing productive faculty from getting on with their job!
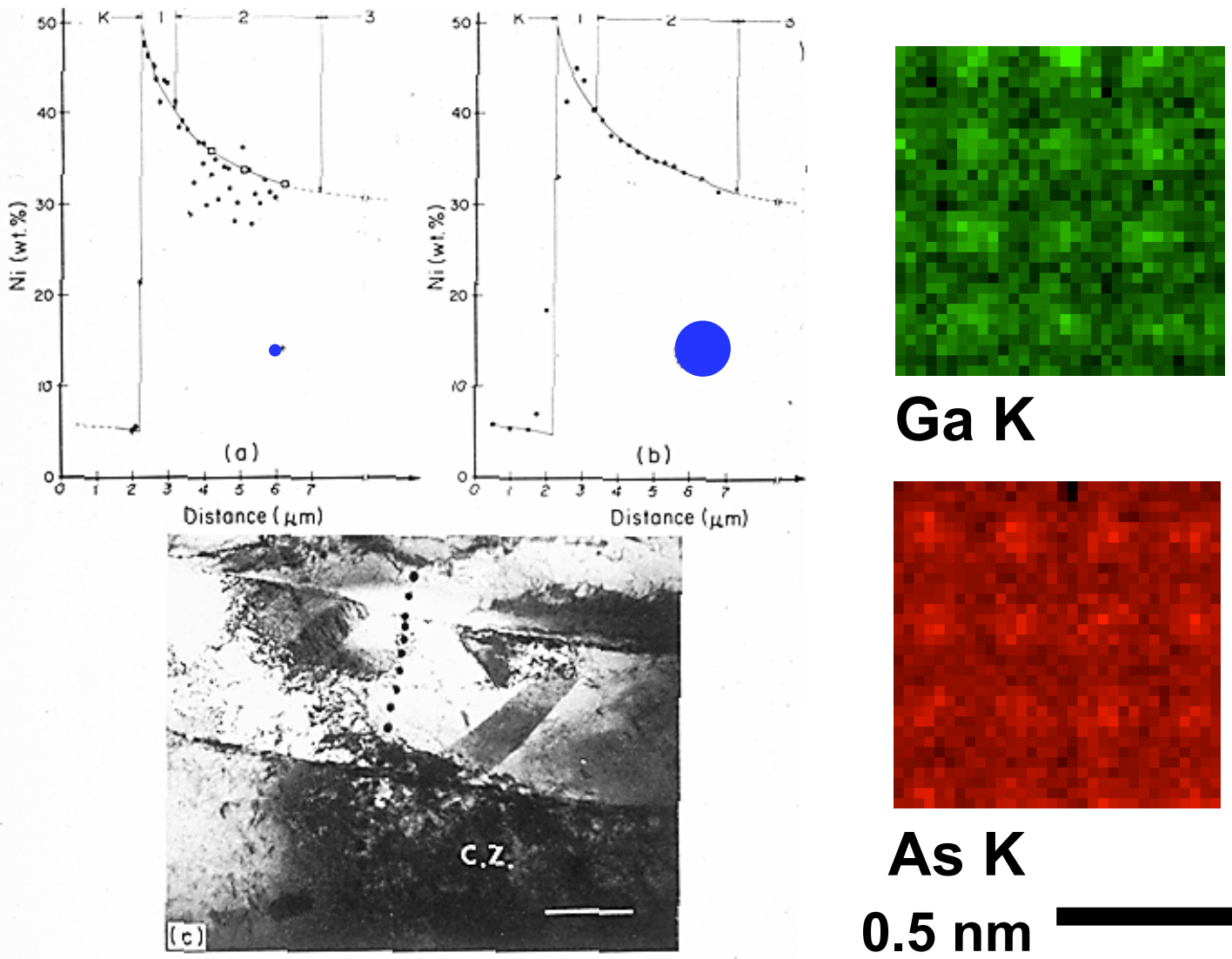

$0.5 \mathrm{~nm}$

Figure 1A) AEM Ni X-ray composition profile and comparison EPMA profile across the $\alpha / \gamma$ interface in an Fe-Ni meteorite. B) X-ray maps of $\mathrm{Ga}$ and As atomic columns. A) modified from JI Goldstein. B) Courtesy, M Watanabe. 